\title{
Effects of feed intake and genetics on tissue nitrogen-15 enrichment and feed conversion efficiency in sheep ${ }^{1}$
}

\author{
L. Cheng, ${ }^{* 2}$ C. M. Logan,* R. J. Dewhurst, $†$ S. Hodge,* H. Zhou,* and G. R. Edwards* \\ *Faculty of Agriculture and Life Sciences, P.O. Box 85084, Lincoln University, Lincoln 7647, \\ New Zealand; and †Scotland’s Rural College, King's Buildings, West Mains Road, Edinburgh EH9 3JG, UK
}

\begin{abstract}
This study investigated the effects of sheep genetics and feed intake on nitrogen isotopic fractionation $\left(\Delta^{15} \mathrm{~N}\right)$ and feed conversion efficiency (FCE; live weight gain/DMI), using a $2 \times 2$ factorial design, with 2 levels of genetic merit for growth (high vs. low) and 2 levels of feed intake (110 vs. $170 \%$ of ME for maintenance $[\mathrm{MEm}])$. No effect of genetic merit was detected for live weight gain $(P=0.64), \operatorname{FCE}(P=0.46)$, plasma urea nitrogen $(P=0.52)$, plasma glucose $(P=$ $0.78)$, and $\Delta^{15} \mathrm{~N}$ of wool $(P=0.45)$, blood $(P=0.09)$, and plasma $(P=0.51)$. Sheep receiving $170 \%$ of MEm had $175 \%$ higher live weight gain $(P<0.001)$ and $77 \%$ higher FCE $(P<0.001)$ than sheep receiving $110 \%$ of
\end{abstract}

MEm. There was no difference among treatments at the beginning of the study for either blood or plasma $\Delta^{15} \mathrm{~N}$, but the treatment groups started to diverge in blood and plasma $\Delta^{15} \mathrm{~N}$ at 21 and $7 \mathrm{~d}$, respectively. Blood, plasma, and wool samples were enriched in ${ }^{15} \mathrm{~N}$ compared with feed. There was a higher blood, plasma, and wool $\Delta^{15} \mathrm{~N}$ for the low feed intake group than the high feed intake group $(P<0.001$ in all cases). Across the 4 treatment groups, higher FCE in sheep was associated with lower $\Delta^{15} \mathrm{~N}$ for plasma, blood, and wool. Overall, the results are consistent with the potential of $\Delta^{15} \mathrm{~N}$ as a rapid, lowcost biomarker of FCE in sheep, despite there being no effects of genetic treatment on FCE and $\Delta^{15} \mathrm{~N}$.

Key words: genetic and nutritional interaction, growth potential, isotopic discrimination, live weight gain, nitrogen-15

(C) 2015 American Society of Animal Science. All rights reserved. J. Anim. Sci. 2015.93:5849-5855 doi: $10.2527 /$ jas2015-9638

\section{INTRODUCTION}

Breeding for increased animal feed conversion efficiency (FCE; live weight $[\mathbf{L W}]$ gain/DMI) is important for a sustainable livestock industry. However, the substantial genetic variation for FCE in cattle and sheep (Berry and Crowley, 2013) has not been exploited because of the difficulty and cost of recording feed intake and LW changes (Herd et al., 2003). Candidate metabolites or hormone biomarkers have

\footnotetext{
${ }^{1}$ Financial support was provided by New Zealand Foundation for Research, Science and Technology and AGMARDT Post-Doctoral Fellowship (Long Cheng). We thank Laura Mansard (Bordeaux Sciences Agro, France), Roger Payne (VSN International), Amy Smaill, Robin McAnulty, Roger Cresswell, Shuang Jiang, Jenny Zhao, Rosy Tung, and Nicole Wheadon (Lincoln University) for technical assistance, laboratory analysis, and useful discussion.

${ }^{2}$ Corresponding author: paul.cheng@lincoln.ac.nz

Received August 4, 2015.

Accepted September 25, 2015.
}

been explored but did not provide consistent relationships with FCE (Kelly et al., 2010; Lawrence et al., 2012). Recently, Wheadon et al. (2014) found a significant negative correlation between FCE and plasma $\mathrm{N}$ isotopic fractionation $\left(\Delta^{\mathbf{1 5}} \mathbf{N}\right.$; animal $\delta^{15} \mathrm{~N}$ - feed $\left.\delta^{1} 5 \mathrm{~N}\right)$ in beef cattle, and similar correlations were also reported in earlier work by Cheng et al. (2013a,b), which showed that $\mathrm{N}$ use efficiency (product $\mathrm{N} / \mathrm{N}$ intake) in sheep and dairy cows was negatively related to $\Delta^{15} \mathrm{~N}$ of muscle and plasma, respectively. Previous work showed the change in $\Delta^{15} \mathrm{~N}$ was related to major $\mathrm{N}$ metabolism reactions such as liver transamination (Macko et al., 1986) and rumen microbial protein synthesis (Wattiaux and Reed, 1995). Although there is tentative evidence for an association between FCE and $\Delta^{15} \mathrm{~N}$ from comparisons of physiological states and effects of dietary treatments that are expected to alter FCE (Sponheimer et al., 2003), it is only recently that the association was confirmed using measurements of FCE for beef cattle offered identical diets (Wheadon et al., 2014). It is not clear if 
Table 1. Average chemical composition (mean and $\mathrm{SD}$ ) of feed samples collected over the 5-wk measurement period $(n=20)$

\begin{tabular}{lcc}
\hline \hline & \multicolumn{2}{c}{ Feed composition } \\
\cline { 2 - 3 } Item & Mean & $\mathrm{SD}$ \\
\hline $\mathrm{DM}, \mathrm{g} / \mathrm{kg}$ & 888 & 5.5 \\
Fat, g/kg DM & 24 & 1.0 \\
$\mathrm{NDF}, \mathrm{g} / \mathrm{kg} \mathrm{DM}$ & 458 & 16.0 \\
Digestible OM in DM, g/kg DM & 607 & 15.4 \\
$\mathrm{CP}, \mathrm{g} / \mathrm{kg} \mathrm{DM}$ & 188 & 6.5 \\
ME, MJ/kg DM & 9.7 & 0.30 \\
\hline
\end{tabular}

such an association would also be observed with other species and also when considering genetic differences between groups of animals and when different diets were offered to animals. The objective of this study was to evaluate sheep genetic and feed intake effects on $\Delta^{15} \mathrm{~N}$ and FCE and the association between $\Delta^{15} \mathrm{~N}$ and FCE and to compare 3 types of samples (blood, plasma, and wool) for determination of $\delta^{15} \mathrm{~N}$ and $\Delta^{15} \mathrm{~N}$.

\section{MATERIALS AND METHODS}

\section{Experimental Design}

Twenty-four 11- to 12-mo-old Coopworth rams were used in this study. Two levels of genetic merit and 2 levels of feed intake were evaluated using a $2 \times$ 2 factorial design. The 4 treatments were high genetic merit + high feed intake (HGHF), high genetic merit + low feed intake (HGLF), low genetic merit + high feed intake (LGHF), and low genetic merit + low feed intake (LGLF). Each treatment group had 6 sheep and they were fed for $1 \mathrm{wk}$ as diet adaptation and $5 \mathrm{wk}$ for LW measurement and sample collection.

\section{Animal Selection, Diet, and Feed Allowance}

The Coopworth flock from Ashley Dene Research Farm, Lincoln University, Lincoln, New Zealand, was used to supply sheep for this study. The high genetic merit (HG) and low genetic merit (LG) groups were selected based on the New Zealand Sheep Improvement Limited (http://www.sil.co.nz/) dual purpose for growth. The selection line and control line were established in 1986 to support a long-term research project investigating the rate of genetic progress using single trait or multitrait selection. The mean (SD) were 1,677 (158.9) New Zealand cents $(\phi)$ and 180 (185.6) New Zealand $\phi$ for HG and LG, respectively. Each group was then divided into 2 subgroups for high feed intake (HF) and low feed intake (LF), balanced for LW measured at the start of the measurement period (Table 1).
All sheep grazed on ryegrass and clover based pasture before the study. Alfalfa pellets (SealesWinslow Ltd., Ashburton, New Zealand) were gradually introduced to the sheep for $1 \mathrm{wk}$ before the study commenced. Two days before the measurement period, sheep were consuming a diet of $100 \%$ alfalfa pellet. Throughout the study, fresh water was offered ad libitum. The feeding allowance was designed to provide either $110 \%$ of ME for maintenance (MEm) for LF groups or 170\% of MEm for HF groups, based on the equation MEm = $0.5 \times \mathrm{LW}^{0.75}$ (Nicol and Brookes, 2007).

\section{Animal Measurements}

The study was undertaken under the authority of Lincoln University Animal Ethics Committee (application number 536). Sheep were individually housed in pens with feed offered once a day at $1030 \mathrm{~h}$. All sheep were weighed (XR 3000; Tru-Test Group, Auckland, New Zealand) after $12 \mathrm{~h}$ overnight fasting at the start and the end of the $5 \mathrm{wk}$ measurement period. Each sheep was offered alfalfa pellets daily, based on calculated feed allowance according to group average LW measured at the start of the measurement period. Feed refusals were recorded to calculate DMI. In addition, FCE was calculated using the equation FCE (g/ $\mathrm{kg})=\mathrm{LW}$ gain $(\mathrm{g} / \mathrm{d}) / \mathrm{DMI}(\mathrm{kg} / \mathrm{d})$. Weekly feed samples from each treatment group were collected and stored at $-20^{\circ} \mathrm{C}$ before compositional and $\delta^{15} \mathrm{~N}$ analysis.

Blood samples were collected from the jugular vein of each sheep into $10 \mathrm{~mL}$ Li-heparinized evacuated tubes at $1430 \mathrm{~h}$ on the first day of measurement Week 1 and at the last day of each measurement week. Blood was subsampled into tubes to harvest plasma by centrifugation at $1,200 \times \mathrm{g}$ for $15 \mathrm{~min}$ at $4^{\circ} \mathrm{C}$ and then both blood and plasma were stored at $-20^{\circ} \mathrm{C}$. A total of 120 blood samples were obtained from this study. There were 9 hemolyzed samples and the corresponding plasma samples were excluded for $\delta^{15} \mathrm{~N}$ and glucose analysis due to contamination of plasma with red blood cells after centrifugation. A 5-mm wool sample per sheep was shaved from skin level $2 \mathrm{wk}$ after the completion of the study (Rogers and Schlink, 2010) for $\delta^{15} \mathrm{~N}$ analysis.

\section{Chemical Analysis}

Alfalfa pellet samples were bulked per treatment at the end of the study and then ground to pass through a 1.0-mm sieve (Christy Lab Mill, Suffolk, UK). The fat, CP, digestible OM in DM (DOMD), and NDF were predicted by near-infrared spectroscopy (Feed and Forage Foss Analyzer 500; FOSS Analytical, Hillerod, Denmark), which is regularly calibrated with results from wet chemistry. The estimated ME content was 
(a)
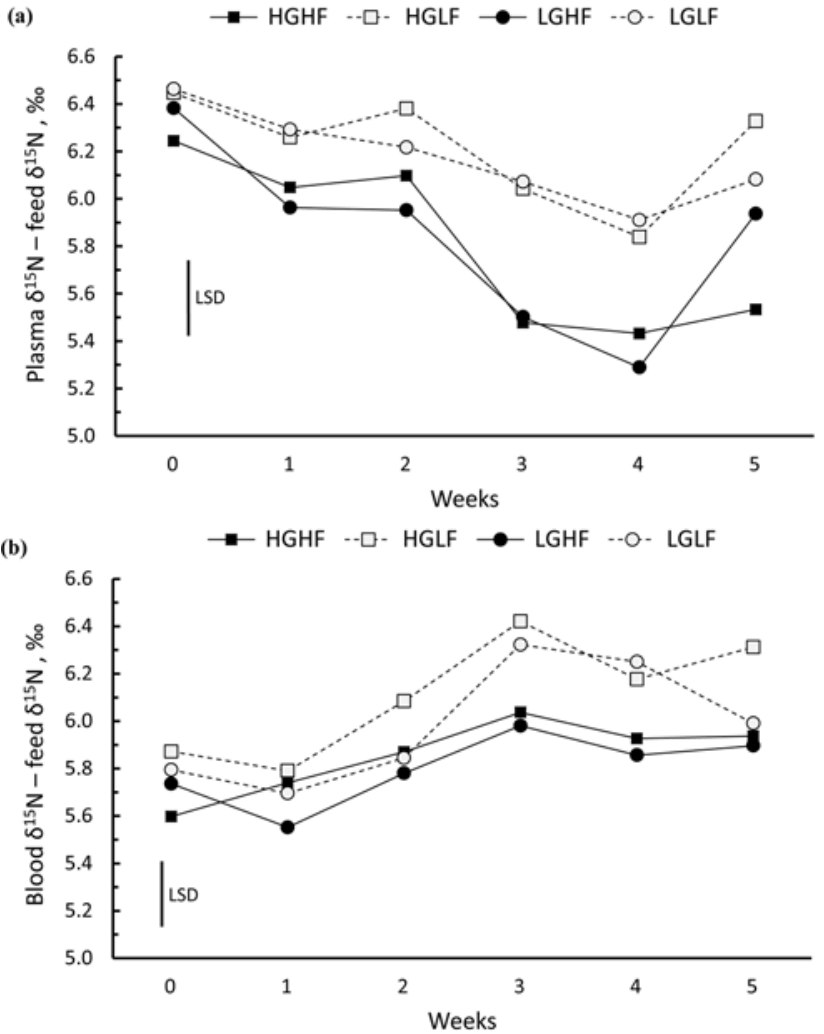

Figure 1. The change of $\mathrm{N}$ isotopic fractionation in plasma (1a) and blood (1b) over $5 \mathrm{wk}$ of measurement period for high $(\mathrm{H})$ and low (L) genetic merit sheep offered high and low feed intake (F). LSD, $P<$ $0.05 . \mathrm{HGHF}=$ high genetic merit + high feed intake; HGLF $=$ high genetic merit + low feed intake; LGHF $=$ low genetic merit + high feed intake; LGLF $=$ low genetic merit + low feed intake.

calculated using the formula from Clarke et al. (1982): $\mathrm{ME}(\mathrm{MJ} / \mathrm{kg} \mathrm{DM})=\operatorname{DOMD}(\mathrm{g} / \mathrm{kg}) \times 0.016$. Feed, blood, plasma, and wool samples were freeze-dried and analyzed for $\delta^{15} \mathrm{~N}$ according to the method described by Cheng et al. (2011) using an isotope-ratio mass spectrometer (PDZ Europa Ltd., Crewe, UK). Plasma urea nitrogen and glucose were analyzed by using an enzymatic kinetic method on a Daytona RX Clinical Analyzer (Randox, Nishonomiya, Japan).

\section{Statistical Analysis}

All statistical analyses were performed using Genstat version 16 (VSN International Ltd., Hemel Hempstead, UK). Results were considered statistically significant at $P<0.05$.

For LW (at Weeks 0 and 5), LW gain, and FCE (over the whole 5 wk experimental period), the effects of feed intake and genetic merit and the interaction between these 2 main factors were assessed by 2-way ANOVA.

Plasma urea $\mathrm{N}$ and glucose data were also analyzed using 2-way ANOVA, with main factors feed intake and genetic merit and the interaction term, based on the mean values for each sheep obtained over the 5-wk experimen- tal period. Wool $\delta^{15} \mathrm{~N}$ and $\Delta^{15} \mathrm{~N}$ data were analyzed by similar 2-way ANOVA based on values obtained from the single measurement of wool $\delta^{15} \mathrm{~N}$ for each sheep.

For blood $\delta^{15} \mathrm{~N}$ and $\Delta^{15} \mathrm{~N}$ and plasma $\delta^{15} \mathrm{~N}$ and $\Delta^{15} \mathrm{~N}$, an antedependence analysis was performed to determine at which weeks from the start of the experiment these variables became independent of preceding values (thus avoiding difficulties related to autocorrelation of data between time points). This antedependence assessment resulted in the data for blood $\Delta^{15} \mathrm{~N}$ from Weeks 4 through 5 and for plasma $\Delta^{15} \mathrm{~N}$ from Weeks 2 through 5 being considered independent from prior values (sees Fig. 1). Therefore, to assess the effects of feed intake and genetic merit on these variables, 2-way ANOVA was performed on the average values for each sheep from Weeks 4 through 5 for blood and Weeks 2 through 5 for plasma.

The way in which the responses of blood $\Delta^{15} \mathrm{~N}$ and plasma $\Delta^{15} \mathrm{~N}$ to feed intake and genetic merit were affected by time from commencement of the different diet regimes were further analyzed using repeated measures ANOVA. For this analysis, any missing values for individual sheep at specific time points were replaced using maximum likelihood estimates.

To examine the relationships between plasma $\Delta^{15} \mathrm{~N}$, blood $\Delta^{15} \mathrm{~N}$, wool $\Delta^{15} \mathrm{~N}$, and FCE, Pearson's correlation coefficient was calculated using the 4 group means.

\section{RESULTS}

The average chemical composition of the alfalfa pellets is shown in Table 1; negligible variation was found over time and between treatment groups for all the components measured.

The HG animals were heavier than the LG animals at both Week 0 and Week $5(P<0.001$; Table 2). Although there was no difference between feed intake groups for LW at the beginning of the study $(P=0.65$; Week 0), the HF animals were heavier than LF at the end of the study (Week 5; $P=0.02$; Table 2). The HF animals had $175 \%$ higher LW gain $(P<0.001)$ and $77 \%$ higher FCE $(P<0.001)$ than the LF animals (Table 2$)$.

The HF animals had higher plasma glucose concentrations than the LF animals $(P=0.01$; Table 3$)$. Blood, plasma, and wool samples measured for $\delta^{15} \mathrm{~N}$ in this study were enriched in ${ }^{15} \mathrm{~N}$ compared with feed. There was significantly higher $\delta^{15} \mathrm{~N}$ and $\Delta^{15} \mathrm{~N}$ for blood, plasma, and wool in the LF groups than in the HF groups $(P<0.001$; Table 3$)$.

There were statistically significant interactions between genetic merit, feed intake, and time points for blood $\Delta^{15} \mathrm{~N}\left(F_{5}, 100=2.90, P=0.04\right)$ and plasma $\Delta^{15} \mathrm{~N}$ $\left(F_{5}, 100=7.09, P<0.001\right)$ over the 5-wk study (Fig. 1$)$. The general trend was that plasma $\Delta^{15} \mathrm{~N}$ decreased over 
Table 2. Dual purpose for growth (DPG), ${ }^{1}$ DMI, live weight (LW) gain, and feed conversion efficiency (FCE) high and low genetic merit sheep offered high and low feed intake (mean; $n=6$ )

\begin{tabular}{l}
\hline Item \\
\hline HGHF
\end{tabular}

the course of the study (Fig. 1a) whereas blood $\Delta^{15} \mathrm{~N}$ tended to increase (Fig. 1b). For plasma $\Delta^{15} \mathrm{~N}$, there was as strong interaction between time and feed intake treatment $\left(F_{5}, 100=8.62, P<0.001\right)$, with the feed intake groups starting to diverge after just $1 \mathrm{wk}$, with the LF group having a higher $\Delta^{15} \mathrm{~N}$ than the HF group (Fig. 1a). A similar significant divergence occurred in the blood $\Delta^{15} \mathrm{~N}\left(F_{5}, 100=4.43, P<0.006\right)$, with the LF group having a higher $\Delta^{15} \mathrm{~N}$ than the HF group, although this time the separation was not so distinct and did not became apparent until Week 3.

The $\Delta^{15} \mathrm{~N}$ for plasma, blood, and wool all responded in a similar way among the 4 treatment groups of sheep, and therefore, significant positive relationships were observed between these variables (Table 4). Conversely, FCE was negatively related to all $3 \Delta^{15} \mathrm{~N}$ measurements (Table 4).

\section{DISCUSSION}

\section{Animal Performance}

Similar trends across the 4 treatment groups were found for LW gain and FCE, with HGHF having the highest values followed by LGHF, LGLF, and HGLF. The higher LW gain and FCE observed for HF animals compared with LF animals is consistent with previous sheep studies (Cottle, 2003; El-Sabagh et al., 2013), and it can be explained by the well-established positive association between DMI and LW gain (Nicol and Brookes, 2007). The higher plasma glucose concentration found in HF animals than in LF animals suggests that more energy is available for rumen fermentation and nutrient absorption of sheep offered HF compared with LF. On the other hand, the higher feeding level may lead to lower MEm cost relative to ME available for LW gain. Such "dilution of maintenance cost" effects allow higher proportions of ME to be used for production, leading to higher LW gain and FCE.

Although genetic effect was not observed for LW gain and FCE, it is interesting to note that $\mathrm{LW}$ gain and FCE were 23 and 14\% higher for LGLF than for HGLF, respectively. This may be related to the different growth potential of LG and HG sheep under restricted feed intake, which relates to the requirement of MEm. The use of $\mathrm{MEm}=0.5 \times \mathrm{LW}^{0.75}$ (Nicol and Brookes, 2007) as a general MEm prediction equation may not be suited for sheep, which differ in growth potential. Previous research suggested that high-producing dairy cows had larger internal organs than low-producing dairy cows (Ferrell and Jenkins, 1984), which can lead to a higher MEm requirement. This is supported by a recent trial in beef cattle, which showed higher FCE (measured as lower residual feed intake) due to a lower weight of the reticulorumen (Fitzsimons et al., 2014). Therefore, different MEm prediction equations may be needed to differentiate genetic differences in maintenance cost of animals.

\section{Feed Conversion Efficiency in Relation to Nitrogen Isotopic Fractionation}

A feature of the results from this study was the strong negative association between the group mean $\Delta^{15 \mathrm{~N}}$ values and FCE. Earlier studies have shown weak associations between FCE and single blood metabolite or hormone measurements. For example, Kelly et al. (2010) reported weak correlations between FCE and plasma leptin $(r 2=0.23)$, urea $(r 2=0.18)$, and NEFA $(r 2=0.10)$ in heifers, and Richardson et al. (2004) found only weak correlations between FCE and plasma glucose $(r 2=0.21)$, aspartate aminotransferase $(r 2=0.20)$, and albumin $(r 2=0.23)$ in steers. Nitrogen isotopic 
Table 3. Plasma urea N, plasma glucose, and N-15 concentrations (delta units expressed relative to standard air; \%o) in the feed, blood, plasma, and wool of high and low genetic merit sheep offered high and low feed intake (mean; $n=6)$

\begin{tabular}{|c|c|c|c|c|c|c|c|c|}
\hline \multirow[b]{2}{*}{ Item } & \multirow[b]{2}{*}{$\mathrm{HGHF}^{1}$} & \multirow[b]{2}{*}{$\mathrm{HGLF}^{1}$} & \multirow[b]{2}{*}{ LGHF $^{1}$} & \multirow[b]{2}{*}{ LGLF $^{1}$} & \multirow[b]{2}{*}{$\mathrm{LSD}^{2}$} & \multicolumn{3}{|c|}{$P$-value } \\
\hline & & & & & & Genetic merit & Feed intake & Genetic merit $\times$ feed intake \\
\hline Plasma urea $\mathrm{N}, \mathrm{mmol} / \mathrm{L}^{3}$ & 8.5 & 7.4 & 8.0 & 8.4 & 1.06 & $\mathrm{NS}^{4}$ & NS & NS \\
\hline Plasma glucose, $\mathrm{mmol} / \mathrm{L}^{3}$ & 3.8 & 3.7 & 4.0 & 3.6 & 0.30 & NS & $*$ & NS \\
\hline Feed $\delta^{15} \mathrm{~N}, \%$ & 0.09 & 0.17 & 0.16 & 0.08 & - & - & - & - \\
\hline Blood $\delta^{15} \mathrm{~N}, \% 0^{5}$ & 5.91 & 6.33 & 5.87 & 6.06 & 0.231 & NS & $* * *$ & NS \\
\hline Plasma $\delta^{15} \mathrm{~N}, \%_{0}{ }^{6}$ & 5.66 & 6.24 & 5.74 & 6.02 & 0.273 & NS & $* * *$ & NS \\
\hline Wool $\delta^{15} \mathrm{~N}, \%{ }^{7}$ & 5.10 & 6.42 & 5.26 & 5.98 & 0.492 & NS & $* * *$ & NS \\
\hline Blood $\Delta^{15} \mathrm{~N}, \% 0^{5}$ & 5.82 & 6.16 & 5.71 & 5.99 & 0.231 & NS & $* * *$ & NS \\
\hline Plasma $\Delta^{15} \mathrm{~N}, \%_{0}{ }^{6}$ & 5.57 & 6.07 & 5.57 & 5.94 & 0.273 & NS & $* * *$ & NS \\
\hline Wool $\Delta^{15} \mathrm{~N}, \%^{7}$ & 5.01 & 6.25 & 5.10 & 5.90 & 0.492 & NS & $* * *$ & NS \\
\hline
\end{tabular}

${ }^{1} \mathrm{HGHF}=$ high genetic merit + high feed intake; HGLF = high genetic merit + low feed intake; LGHF = low genetic merit + high feed intake; $\mathrm{LGLF}=$ low genetic merit + low feed intake.

${ }^{2} P<0.05$.

${ }^{3}$ Based on a mean value for each sheep over the $5 \mathrm{wk}$ of the experiment.

${ }^{4} \mathrm{NS}=$ non-significant.

${ }^{5}$ Based on a mean value for each sheep from Weeks 4 through 5 .

${ }^{6}$ Based on a mean value for each sheep from Weeks 2 through 5 .

${ }^{7} \mathrm{Based}$ on a single value for each sheep taken $2 \mathrm{wk}$ after completion of the study.

$* P<0.05 ; * * * P<0.001$.

fractionation provided a good indication of FCE in this study, and it seems likely that this association was driven by the partitioning of $\mathrm{N}$ between $\mathrm{LW}$ gain and excretion in urine. The negative association between $\Delta^{15} \mathrm{~N}$ and FCE is consistent with the increased $\Delta^{15} \mathrm{~N}$ when cattle and goats were fed diets containing higher protein levels (Sponheimer et al., 2003). It is also supported by the findings of Wheadon et al. (2014), who showed a strong negative relationship between individual cattle FCE and plasma $\Delta^{15} \mathrm{~N}$ when they were offered the same diet.

\section{Nitrogen Isotopic Fractionation}

The enrichment of wool, plasma, and blood in ${ }^{15} \mathrm{~N}$ compared with feed is consistent with the literature (Koyama, 1985; Sponheimer et al., 2003). The main reason for the enrichment of ${ }^{15} \mathrm{~N}$ in these samples was probably due to the major $\mathrm{N}$ components being true protein or AA, which are naturally enriched in ${ }^{15} \mathrm{~N}$ (Sick et al., 1997; Cheng et al., 2010). The average levels of plasma $\Delta^{15} \mathrm{~N}$ in this study was $5.66 \%$, which is in the upper end of the range previously reported for both lactating and nonlactating ruminants (Cheng et al., 2013b; Wheadon et al., 2014). The reason for this high plasma $\delta^{15} \mathrm{~N}$ value in the current study is not clear, but it may be related to the maturity of the animals. Despite the high LW gain observed from the sheep used in this study, the sheep were close to maturity (Cottle, 2003), so an increased level of fat deposition might contribute to LW gain. Higher $\Delta^{15} \mathrm{~N}$ in tissues should be expected from these sheep compared with younger individuals because mature sheep utilize feed protein less efficiently than suckling or lactating ani- mals (Wheadon et al., 2014). For this reason, the stage of maturity of animals should also be considered when discussing isotopic fractionation in animal tissues.

A strong positive relationship was observed between $\Delta^{15} \mathrm{~N}$ in plasma and blood, and this is expected as plasma is a fraction of blood. Blood was relatively more enriched in ${ }^{15} \mathrm{~N}$ than plasma in this study. This is because red blood cells in the blood contain mostly true protein, which is enriched in ${ }^{15} \mathrm{~N}$ relative to the urea containing plasma (Sick et al., 1997). Furthermore, it may be related to differences in the AA profile of free and protein-bound AA in plasma and red blood cells. For example, serine is a major AA in red blood cells but is not found in plasma (Canepa et al., 2002). Serine had a high isotopic fractionation factor among the 17 AA analyzed by Zhang and Altabet (2008). The positive relationship between plasma and wool $\Delta^{15} \mathrm{~N}$ in this study may be related to $\Delta^{15} \mathrm{~N}$ during digestion and absorption or an effect of the endogenous contribution to the protein synthesized in the samples.

Variation in the $\Delta^{15} \mathrm{~N}$ of blood and plasma was observed over the 5 -wk study. Because $\Delta^{15} \mathrm{~N}$ has already been corrected for differences in dietary $\delta^{15} \mathrm{~N}$, this difference is most likely derived from the variation in protein turnover rates (Ben-David et al., 2012). Results from this study are consistent with a higher turnover rate of protein in plasma than in blood, which is in agreement with previous reports concerning a range of mammals (Hilderbrand et al., 1996; Lecomte et al., 2011; Ben-David et al., 2012).

The causes of the differences in turnover rates of $\Delta^{15} \mathrm{~N}$ in blood and plasma are mainly due to their con- 
Table 4. Correlation coefficients ( $r_{\mathrm{p}}$; upper values) and $P$-values (lower values) between group means for feed conversion efficiency (FCE), plasma $\Delta^{15} \mathrm{~N}$, blood $\Delta^{15} \mathrm{~N}$, and wool $\Delta^{15} \mathrm{~N}$ (mean; $\left.n=4\right)$

\begin{tabular}{lrcc}
\hline \hline Item & FCE & Plasma $\Delta^{15} \mathrm{~N}$ & Blood $\Delta^{15} \mathrm{~N}$ \\
\hline Plasma $\Delta^{15} \mathrm{~N}$ & -0.995 & & \\
& 0.005 & & \\
Blood $\Delta^{15} \mathrm{~N}$ & -0.964 & 0.961 & \\
& 0.036 & 0.039 & \\
Wool $\Delta^{15} \mathrm{~N}$ & -0.997 & 0.998 & 0.950 \\
& 0.003 & 0.002 & 0.050 \\
\hline
\end{tabular}

stituent proteins. The major proteins in plasma and blood are albumin and hemoglobin, respectively, and the halflife of albumin is much shorter (approximately $14 \mathrm{~d}$ ) than that of hemoglobin (approximately $120 \mathrm{~d}$; Rendell et al., 1987). This would suggest that $14 \mathrm{~d}$ may be a conservative lower limit for plasma protein turnover in sheep. The predicted blood ${ }^{15} \mathrm{~N}$ half-life is approximately $20 \mathrm{~d}$, when assuming a blood cell-to-plasma ratio of 45:55 and adopting 40 and $4 \mathrm{~d}$ as the respective half-lives of each tissue type (Lecomte et al., 2011).

\section{Conclusions}

Overall, the results are consistent with the potential of using $\Delta^{15} \mathrm{~N}$ as a rapid, low-cost biomarker of FCE in sheep, despite there being no effects of genetic treatment on FCE and $\Delta^{15} \mathrm{~N}$. Future studies on longer-term and complicated genetic and environmental interactions (e.g., different genotypes fed on different types and quantities of feed) should be explored, using both mature and growing animals, to confirm the value of using $\Delta^{15} \mathrm{~N}$ as a performance measure across entire sheep production systems.

\section{LITERATURE CITED}

Ben-David, M., S. D. Newsome, and J. P. Whiteman. 2012. Lipid and amino acid composition influence incorporation and discrimination ok ${ }^{13} \mathrm{C}$ and ${ }^{15} \mathrm{~N}$ in mink. J. Mammal. 93:399-412. doi:10.1644/11-MAMM-S-168.1.

Berry, D. P., and J. J. Crowley. 2013. Cell biology symposium: Genetics of feed efficiency in dairy and beef cattle. J. Anim. Sci. 91:1594-1613. doi:10.2527/jas.2012-5862.

Canepa, A., J. C. D. Filho, A. Gutierrez, A. Carrea, A. M. Forsberg, E. Nilsson, F. Perfumo, and J. Bergström. 2002. Free amino acids in plasma, red blood cells, polymorphonuclear leukocytes, and muscle in normal and uraemic children. Nephrol. Dial. Transplant. 17:413-421. doi:10.1093/ndt/17.3.413.

Cheng, L., R. J. Dewhurst, J. Larkin, F. Buckley, C. Thackaberry, A. M. Nicol, and G. R. Edwards. 2010. Brief communication: Investigation of $\mathrm{N}$ isotopic fractionation in dairy cows using milk samples collected at the morning and afternoon milkings. Proc. N. Z. Soc. Anim. Prod. 70:65-66.
Cheng, L., E. J. Kim, R. J. Merry, and R. J. Dewhurst. 2011. Nitrogen partitioning and isotopic fractionation in dairy cows consuming diets based on a range of contrasting forages. J. Dairy Sci. 94:2031-2041. doi:10.3168/jds.2010-3763.

Cheng, L., A. M. Nicol, R. J. Dewhurst, and G. R. Edwards. 2013a. The effects of dietary nitrogen to water-soluble carbohydrate ratio on isotopic fractionation and partitioning of nitrogen in non-lactating sheep. Animal 7:1274-1279. doi:10.1017/ S1751731113000311.

Cheng, L., A. J. Sheahan, S. J. Gibbs, A. G. Rius, J. K. Kay, S. Meier, G. R. Edwards, R. J. Dewhurst, and J. R. Roche. 2013b. Technical note: Nitrogen isotopic fractionation can be used to predict nitrogen-use efficiency in dairy cows fed temperate pasture and supplemented with urea. J. Anim. Sci. 91:5785-5788. doi:10.2527/jas.2012-5378.

Clarke, T., P. C. Flinn, and A. A. McGowan. 1982. Low-cost pepsin-cellulase assays for prediction of digestibility of herbage. Grass Forage Sci. 37:147-150. doi:10.1111/j.1365-2494.1982. tb01590.x.

Cottle, D. J. 2003. Sheep breeds. In: Australian sheep and wool handbook. WRONZ Developments, Christchurch, New Zealand. p. 19-63.

El-Sabagh, M., M. Goto, T. Sugino, T. Obitsu, and K. Taniguchi. 2013. Energy metabolism by splanchnic tissues of mature sheep fed varying levels of alfalfa hay cubes. Animal 7:1622-1630. doi:10.1017/S1751731113001225.

Ferrell, C. L., and T. G. Jenkins. 1984. Relationships among various body components of mature cows. J. Anim. Sci. 58:222-233.

Fitzsimons, C., D. A. Kenny, and M. McGee. 2014. Visceral organ weights, digestion and carcass characteristics of beef bulls differing in residual feed intake offered a high concentrate diet. Animal 8:949-959. doi:10.1017/S1751731114000652.

Herd, R. M., J. A. Archer, and P. F. Arthur. 2003. Reducing the cost of beef production through genetic improvement in residual feed intake: Opportunity and challenges to application. J. Anim. Sci. 81(Suppl. 1):E9-E17.

Hilderbrand, G. V., S. D. Varley, C. T. Robbins, T. A. Hanley, K. Titus, and C. Servheen. 1996. Use of stable isotopes to determine diets of living and extinct bears. Can. J. Zool. 74:20802088. doi:10.1139/z96-236.

Kelly, A. K., M. McGee, and D. H. Crews. 2010. Effect of divergence in residual feed intake on feeding behavior, blood metabolic variables, and body composition traits in growing beef heifers. J. Anim. Sci. 88:109-123. doi:10.2527/jas.2009-2196.

Koyama, M. 1985. Fractionation of nitrogen isotopes by domestic animals. Jpn. J. Zootech. Sci. 56:361-362.

Lawrence, P., D. A. Kenny, and B. Earley. 2012. Grazed grass herbage intake and performance of beef heifers with predetermined phenotypic residual feed intake classification. Animal 6:1648-1661. doi:10.1017/S1751731112000559.

Lecomte, N., Ø. Ahlstrom, D. Ehrich, E. Fuglei, R. A. Ims, and N. G. Yoccoz. 2011. Intrapopulation variability shaping isotope discrimination and turnover: Experimental evidence in Artic Foxes. PLoS One 6:E21357. doi:1371/journal.pone.0021357.

Macko, S. A., M. L. Fogel, M. H. Engel, and P. E. Hare. 1986. Kinetic fractionation of stable nitrogen isotopes during amino acid transamination. Geochim. Cosmochim. Acta 50:2143-2146. doi:10.1016/0016-7037(86)90068-2.

Nicol, A. M., and I. M. Brookes. 2007. The metabolisable energy requirements of grazing livestock. In: P. V. Rattray, I. M. Brookes, and A. M. Nicol, editors, Pasture and supplements for grazing animals. Soc. Anim. Prod. Occasional Publication, Cambridge, NZ. p. 151-173. 
Rendell, M., C. Brannan, J. Nierenberg, K. Rasbold, and T. Hestorff. 1987. Fingerstick glycosylated hemoglobin, plasma protein, and albumin. Diabetes Care 10:629-632. doi:10.2337/diacare.10.5.629.

Richardson, E. C., R. M. Herd, and J. A. Archer. 2004. Metabolic differences in Angus steers divergently selected for residual feed intake. Aust. J. Exp. Agric. 44:441-452. doi:10.1071/EA02219.

Rogers, G. E., and A. C. Schlink. 2010. Wool growth and production. In: D. J. Cottle, editor, International sheep and wool handbook. Nottingham Univ. Press, Christchurch, New Zealand. p. 373-394.

Sick, H., N. Roos, E. Saggau, K. Haas, V. Meyn, B. Walch, and N. Trugo. 1997. Amino acid utilization and isotope discrimination of amino nitrogen in nitrogen metabolism in rat liver in vivo. $\mathrm{Z}$. Ernahrungswiss. 36:340-346. doi:10.1007/BF01617819.
Sponheimer, M., T. Robinson, L. Ayliffe, B. Roeder, J. Hammer, B. Passey, A. West, T. Cerling, D. Dearing, and J. Ehleringer. 2003. Nitrogen isotopes in mammalian herbivores: Hair $\delta^{15} \mathrm{~N}$ values from a controlled feeding study. Int. J. Osteoarchaeol. 13:80-87. doi:10.1002/oa.655.

Wattiaux, M. A., and J. D. Reed. 1995. Fractionation of nitrogen isotopes by mixed ruminal bacteria. J. Anim. Sci. 73:257-266.

Wheadon, N. M., M. McGee, G. R. Edwards, and R. J. Dewhurst. 2014. Plasma nitrogen fractionation and feed efficiency in growing beef heifers. Br. J. Nutr. 111:1705-1711. doi:10.1017/S0007114513004078.

Zhang, L., and M. A. Altabet. 2008. Amino-group-specific natural abundance nitrogen isotope ratio analysis in amino acids. Rapid Commun. Mass Spectrom. 22:559-566. doi:10.1002/rcm.3393. 